\title{
Photoelectrochemical treatment of landfill leachate in a continuous flow reactor
}

\author{
Xu Zhao, Jiuhui Qu* , Huijuan Liu, Chunxia Wang, Shuhu Xiao, Ruiping Liu, Pengju Liu, Huachun Lan, \\ Chengzhi Hu
}

State Key Laboratory of Environmental Aquatic Chemistry, Research Center for Eco-Environmental Sciences, Chinese Academy of Sciences, Beijing 100085, PR China

\section{A R T I C L E I N F O}

\section{Article history:}

Received 23 May 2009

Received in revised form 25 August 2009

Accepted 25 August 2009

Available online 30 September 2009

\section{Keywords:}

Landfill leachate

Photoelectrochemical treatment

Flow reactor

Electrolysis

UV light irradiation

\begin{abstract}
A B S T R A C T
Leachate from a municipal landfill site, which has been treated by biological process, was treated by photoelectrochemical oxidation in a pilot scale flow reactor, using DSA anode and UV light irradiation. At a current density of $67.1 \mathrm{~mA} / \mathrm{cm}^{2}$ and $2.5 \mathrm{~h}$ reaction time, the removal rates achieved were for $74.1 \%$ COD, $41.6 \%$ for TOC, and $94.5 \%$ for ammonium in the electrolysis process with UV light irradiation. In comparison, the removal rates of COD, TOC, and ammonium were decreased in the individual electrolysis process, respectively. The increase induced by the UV light irradiation was analyzed. The removal rates increased with the increase of current densities in the photoelectrochemical process. Combined with UV-vis spectra and gas chromatography-mass spectroscopy analysis, it is believed that the organic contaminants were efficiently mineralized into small molecular acids. At the meantime, the concentrations of metal ions in the landfill leachate were largely reduced.
\end{abstract}

(c) 2009 Elsevier Ltd. All rights reserved.

\section{Introduction}

Sanitary landfills are the primary method currently used for municipal solid waste disposal in many countries, and leachate generated from landfills is a high-strength wastewater exhibiting acute and chronic toxicity (Fan et al., 2008; Renou et al., 2008; Salem et al., 2008). Untreated leachates can permeate groundwater or mix with surface water and contribute to the pollution of soil, groundwater, and surface water (Salem et al., 2008). Biological methods are very effective for the treatment of landfill leachate with a high value of biological oxygen demand (BOD) but are ineffective if recalcitrant compounds are present, so that a physical-chemical process is required (Lei et al., 2007). Great attention has been directed toward either new chemical and physical processes or traditional methods (Rivas et al., 2005; Primo et al., 2008). $\mathrm{O}_{3}, \mathrm{O}_{3} / \mathrm{H}_{2} \mathrm{O}_{2}$, and $\mathrm{O}_{3} / \mathrm{UV}$ have been used in treating landfill leachate recently (Wu et al., 2004). The Fenton reaction (Deng and Englehardt, 2006) and heterogeneous photocatalysis have also been proved to be an alternative as a tertiary treatment (Cho et al., 2002). Generally, the above advanced oxidation processes depends on hydroxyl radicals' reaction. Landfill leachate had high concentration of alkalinity that can react with hydroxyl radicals with high reaction rate. Therefore, alkalinity need to be removed by $\mathrm{pH}$ adjustment before these reactions (Cho et al., 2004).

Electrochemical technology offers an efficient means of controlling pollution and it has become available in the last two decades.

\footnotetext{
* Corresponding author. Tel.: +86 1062849151 ; fax: +86 1062923558 .

E-mail address: jhqu@mail.rcees.ac.cn (J. Qu).
}

Application of electrochemical methods in treating landfill leachate has been investigated (Cossu et al., 1998; Moraes and Bertazzoli, 2005; Cabeza et al., 2007; Anglada et al., 2009). Generally, high concentration of $\mathrm{Cl}^{-}$was present in the landfill leachate. In the electrolysis of landfill leachate, indirect oxidation induced by the active chloride radicals will occur, which are not dependant on the hydroxyl radicals. Thus, the organic contaminants and $\mathrm{NH}_{3}-\mathrm{N}$ will be removed in the electrolysis process (Chiang et al., 1995a).

Recently, photoelectrochemical (PEC) oxidation has been proven an efficient method in removing organic contaminants than individual electrolysis and photocatalysis process. It has been reported that the landfill leachate can be efficiently removed by photo-assisted electrolysis method (Tauchert et al., 2006). In that work, the PEC treatment permits almost total decolonization and typical COD removal of about $60 \%$ within $300 \mathrm{~min}$. And, the static PEC process was carried out in a glass reactor with $1 \mathrm{~L}$ of capacity, equipped with water refrigeration and magnetic stirring. The cathode and anode were titanium grid and DSA commercial, respectively. In the current work, a pilot scale flow electrochemical reactor was used for landfill leachate treatment with the assistance of UV light irradiation. In comparison with the electrolysis process, an obvious increase in the removal of $\mathrm{NH}_{3}-\mathrm{N}, \mathrm{COD}, \mathrm{TOC}$, and BOD were observed in the PEC process. The enhanced mechanism was analyzed; effects of current densities and reaction time were investigated.

\section{Methods}

PEC process was carried out in a reactor with $6.5 \mathrm{~L}$ capacity. The tubular DSA anode was concentrically located at the center of the 


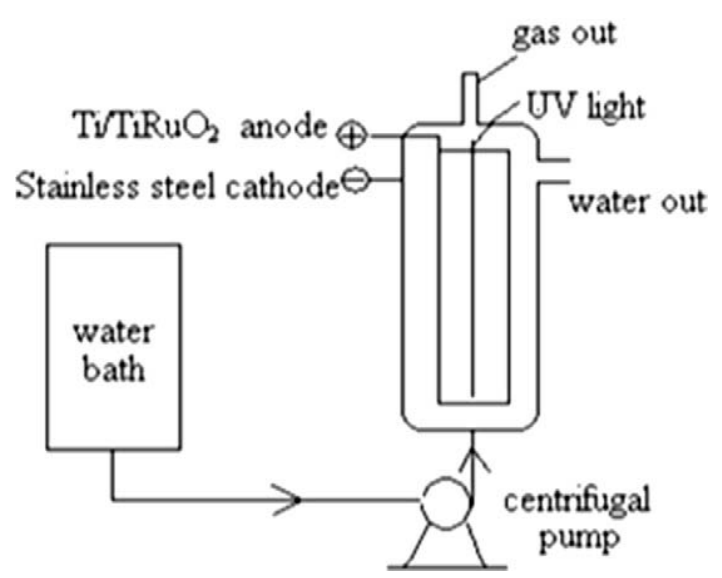

Fig. 1. Photoelectrochemical reaction system used in the current study.

reactor. The dimension and length of the tubular DSA anode was $60 \mathrm{~mm}$ and $1125 \mathrm{~mm}$, respectively. The stainless steel outside of the reactor was also used as the cathode. A UV lamp (20 W, main wavelength $254 \mathrm{~nm}$ ) in a quartz glass tube was located at the center of the reactor. The system was submitted to various current densities controlled by a DC-stabilized power with a maximum output of $300 \mathrm{~A}$ and $10 \mathrm{~V}$. The setup is described in Fig. 1.

Leachate samples with biological treatment were collected from a sanitary landfill located in the city of Beijing and stored at a temperature of $4{ }^{\circ} \mathrm{C}$ for a maximum of 10 days in order to maintain their characteristics. In Table 1, the initial characteristics of the landfill leachate is presented. After biological treatment, the $\operatorname{COD}_{\mathrm{Cr}}$, $\mathrm{TOC}$, and $\mathrm{NH}_{3}-\mathrm{N}$ are still high. And, the chlorine concentration is as high as $4500 \mathrm{mg} / \mathrm{L}$.

The experiment was operated in a continuous flow mode. During the experiments, leachate samples were periodically collected for analysis. No reactants or supporting electrolyte were added to the leachate prior to the experiments. The progress of electrochemical oxidation was monitored by measuring COD and TOC. The concentrations of COD were determined with a COD analyzer (HATO ${ }^{\circledR}$ CTL-12, China). The TOC was determined with multi N/C 3000 TOC analyzer (Analytik Jena AG Co., Germany) after the solution was filtered through a $0.45 \mu \mathrm{m}$ filter. UV-vis spectra of the samples were recorded on a U-3010 UV-vis spectrophotometer (Hitachi Co., Japan). The values of $\mathrm{pH}$ were measured using an Orion 720APLUS Benchto meter (Thermo Orion Co., USA). For gas chromatography-mass spectroscopy (GC-MS) analysis, the residue was trimethylsilylated with $0.2 \mathrm{~mL}$ of anhydrous pyridine, $0.1 \mathrm{~mL}$ of hexamethyldisilazane, and $0.05 \mathrm{~mL}$ of chlorotrimethylsilane at room temperature. GC-MS analysis was carried out on an Agilent $6890 G C / 5973 M S D$ with a DB-5 MS capillary column. The concentration of metal ions in the landfill leachates was examined via an ICP-OES (SCIEX Perkin Elmer Elan mode 5000). Before the mea-

Table 1

Characteristics of the landfill leachate.

\begin{tabular}{ll}
\hline Parameter & Content \\
\hline $\mathrm{pH}$ & 7.80 \\
Conductivity $\left(\mathrm{mS} \mathrm{cm}^{-1}\right)$ & 14.74 \\
Alkalinity $\left(\mathrm{CaCO}_{3}\right)$ & 6300 \\
$\mathrm{TDS}^{\mathrm{a}}$ & 8150 \\
$\mathrm{COD}$ & 560 \\
$\mathrm{TOC}$ & 190 \\
$\mathrm{NH}_{3}-\mathrm{N}$ & 700 \\
Chlorine & 4500 \\
\hline
\end{tabular}

a Average values. Units in $\mathrm{mg} / \mathrm{L}$. surement, the $\mathrm{pH}$ values of landfill leachates were adjusted to 2.0 in order to dissolve the metal oxides.

\section{Results and discussion}

\subsection{Degradation characteristics of landfill leachate in EC and PEC process}

As shown in Fig. 2A, in individual EC process, within $2.5 \mathrm{~h}$, ammonium was efficiently removed, $47.5 \%$ COD and $28.3 \%$ TOC were removed, respectively. By contrast, in PEC process, nearly 74.1\% COD and $41.6 \%$ TOC were removed. These results indicated that UV light irradiation increased the removal rate of COD and TOC in the leachate efficiently. As shown in Fig. 2B, all the values of $\mathrm{BOD}_{5} / \mathrm{COD}$ in $\mathrm{EC}$ and $\mathrm{PEC}$ processes were increased with the evolution of reaction time. Furthermore, it can be seen from Fig. 2B that the increased value of $\mathrm{BOD}_{5} / \mathrm{COD}$ in PEC process is larger than that in the individual EC process, which confirmed the advantage of PEC process. At the meantime, nearly no reduction of COD, TOC, and $\mathrm{BOD}_{5}$ in the individual photolysis process was observed (data not shown).

In EC process, oxidant species such as hydroxyl radicals will form on the anode surface. On the other hand, chloride ions usually
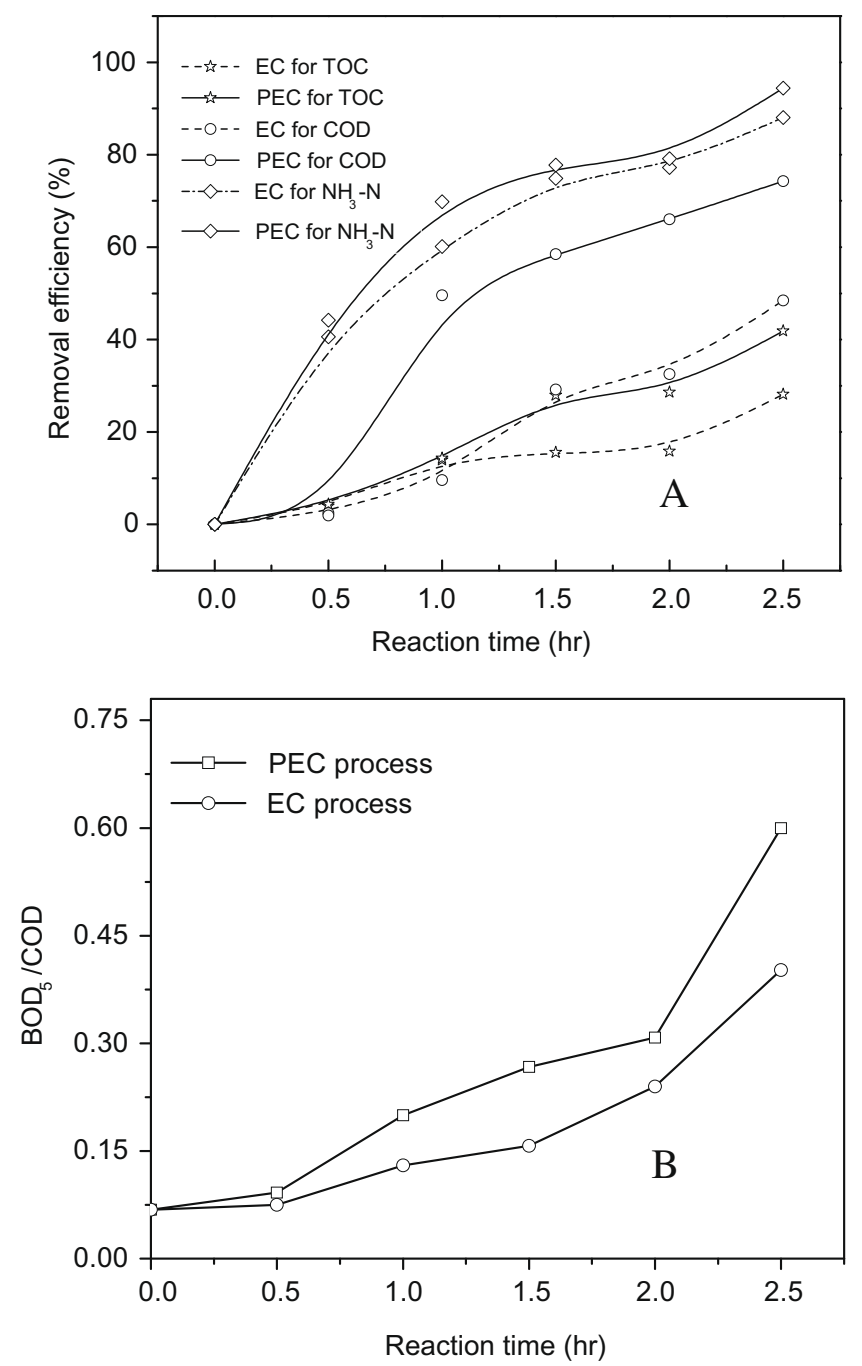

Fig. 2. (A) Degradation characteristic of landfill leachate in EC and PEC process with the current density of $67.1 \mathrm{~mA} / \mathrm{cm}^{2}$ and reaction time of $2.5 \mathrm{~h}$; (B) changes of $\mathrm{BOD}_{5} /$ COD with the time in EC and PEC processes with current densities of $67.1 \mathrm{~mA} / \mathrm{cm}^{2}$ and reaction time of $2.5 \mathrm{~h}$. 


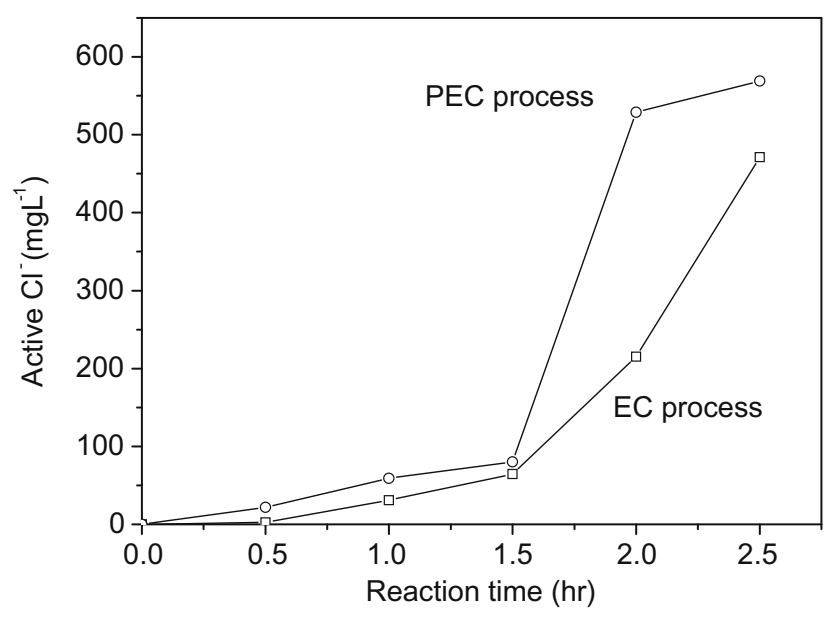

Fig. 3. Variation of active $\mathrm{Cl}^{-}$amount with the time in EC and PEC processes with the current densities of $67.1 \mathrm{~mA} / \mathrm{cm}^{2}$ and reaction time of $2.5 \mathrm{~h}$.

present in landfill leachates are oxidized to chlorine/hypochlorite. All of these oxidation species are responsible for the oxidation of organic pollutants and ammonium removal.

In PEC process, COD reduction efficiency ranges from $70 \%$ to above $90 \%$, and ammonium removal efficiency almost reaches
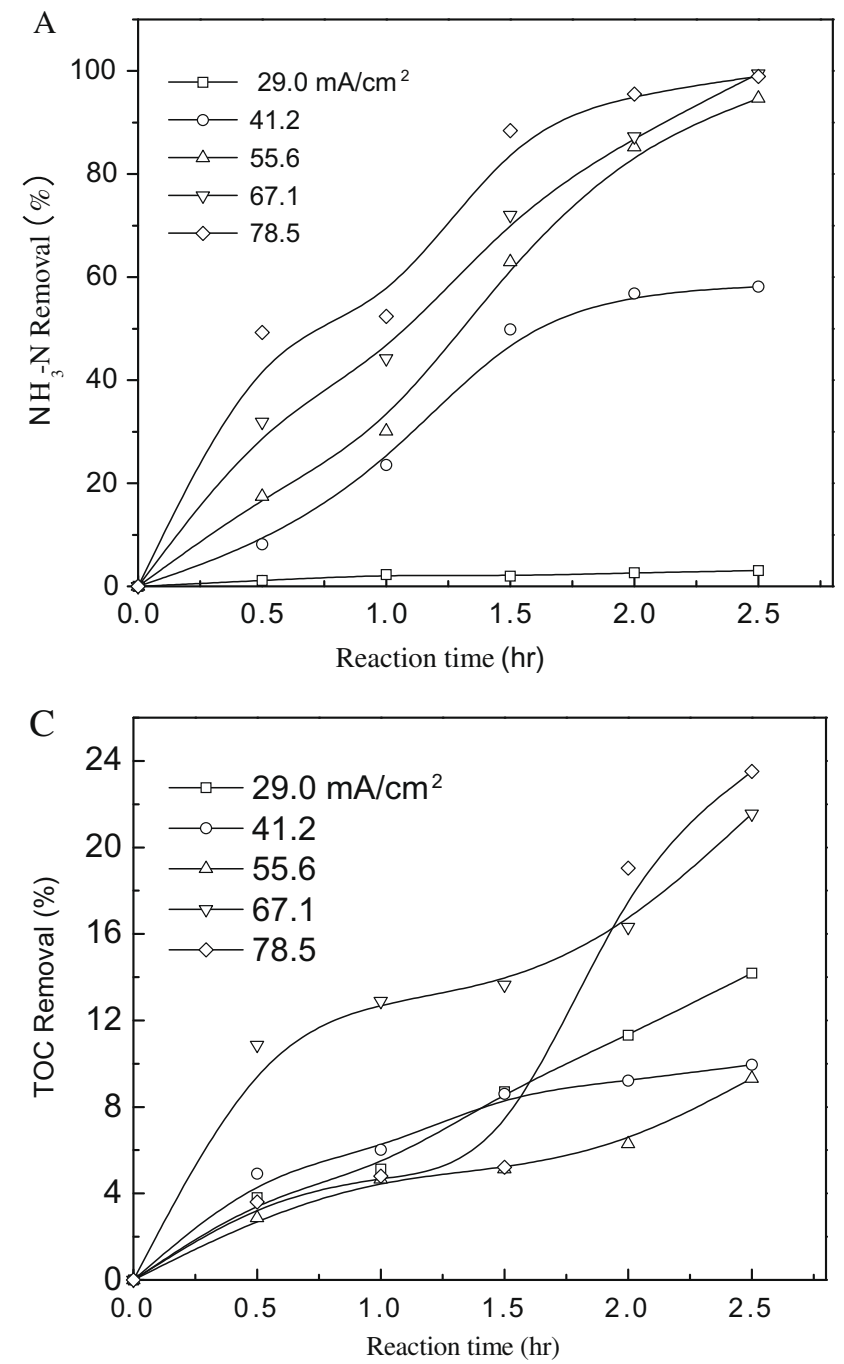

$100 \%$ under appropriate conditions. Chiang et al. (1995b) found that removal of ammonium was obviously dominant when in competition with removal of COD under indirect oxidation during electro-oxidation of an old leachate. Cossu et al. (1998) reported that the removal rate of ammonium was lower than that of COD at the initial stage of electro-oxidation of an old leachate when direct oxidation predominated, and then ammonium was substantially removed in the subsequent electro-oxidation stage when indirect oxidation became prevalent. Our results are consistent with the above conclusions. The variation of active $\mathrm{Cl}^{-}$amount in the reaction solution was examined in PEC and EC processes, respectively. It can be seen from Fig. 3 that more active $\mathrm{Cl}^{-}$radicals were produced in PEC process than that in EC process, which may be responsible for the more efficient removal of COD in PEC process than that in EC process.

\subsection{Effect of applied current densities on PEC degradation of landfill leachate}

Current density, the current per unit area of electrode, may be the most frequently referred term in an electrochemical process because it controls the reaction rate. It can be seen from Fig. 4 that nearly no removal of ammonium and COD was observed at the current density of $29.0 \mathrm{~mA} / \mathrm{cm}^{2}$. With the increase of current density, ammonium and COD were obviously removed; the removal rate
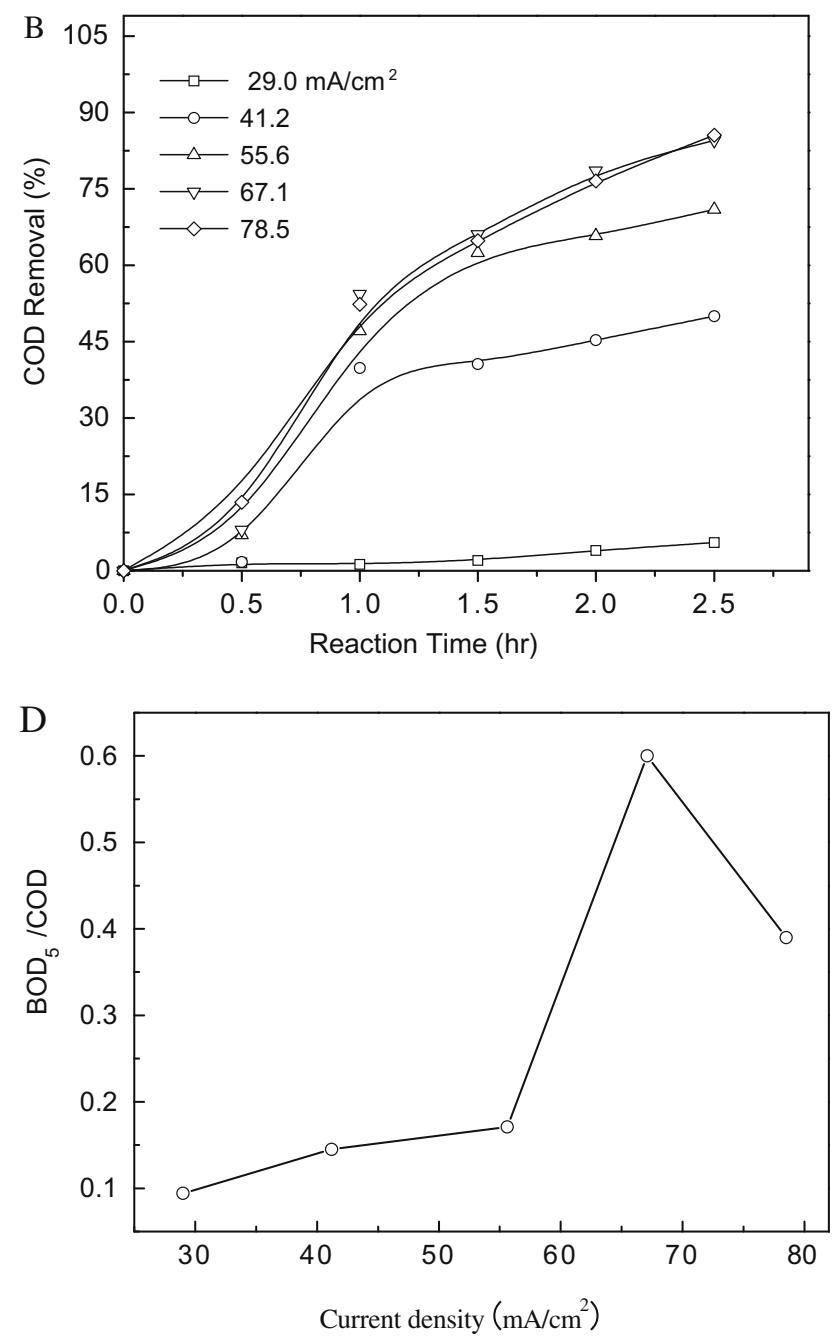

Fig. 4. Effect of current densities on PEC degradation of landfill leachate. (A) $\mathrm{NH}_{3}-\mathrm{N}$; (B) COD removal; (C) TOC removal; (D) BOD $5 / C O D$. 
increased with the current density. A possible explanation is that an increased current density during electro-oxidation enhanced chlorine generation, which was probably responsible for subsequent removal of ammonium. Chiang et al. (1995b) reported that during electro-oxidation of leachate with the current density of $25.00 \mathrm{~mA} / \mathrm{cm}^{2}$, COD removal efficiency was about $50 \%$ higher than that by electro-oxidation with $6.25 \mathrm{~mA} / \mathrm{cm}^{2}$. In our case the $\mathrm{Cl}^{-}$ concentration was high as $4500 \mathrm{mg} / \mathrm{L}$. Thus, the indirect oxidation plays a predominant role in the removal of COD and ammonium.

During the electrochemical oxidation of landfill leachate, pollutant removal may be primarily due to indirect oxidation, utilizing chlorine/hypochlorite formed by anodic oxidation of chlorine originally existing or added in the leachate, although direct anodic oxidation may to some extent destroy pollutants adsorbed on the anode surface. Hypochlorite generated is a strong oxidant that can oxidize aqueous organic compounds. Chiang et al. (1995b) found that COD and ammonium removal efficiencies in electrooxidation of leachate increased with the current density. However, in a direct electrochemical oxidation, pollutant removal efficiency at the same charge loading (in coulomb per litre) is independent of current density. Hence, Chiang et al. (1995a) suggested that indirect oxidation was the main process during electrochemical oxidation of leachate. Moreover, they proposed that ammonium removal can be due to a series of reactions between hypochlorite and ammonia.

\subsection{Analysis of organic contaminants in landfill leachate in PEC process}

It can be seen from Fig. 5 that the solution pH decreases with the extension of reaction time under various current densities. In PEC reaction, the ammonium was removed and some organic pollutants with large molecular weight were degraded into some organic acids or small molecular acids, which are responsible for the decrease of solution $\mathrm{pH}$. The UV-vis spectra variation with the reaction time was shown in Fig. 6 . It is shown that the intensity increase at the initial $30 \mathrm{~min}$ and decrease subsequently when the wavelength was less than $300 \mathrm{~nm}$. When the wavelength was larger than $300 \mathrm{~nm}$, the wavelength decrease throughout the reaction time. These results indicate that some intermediates produced at the initial reaction time, which were subsequently degraded with the reaction evolution. As shown in Supplementary material of Fig. 1, the organic pollutants in the leachate are largely reduced after PEC reaction for $2.5 \mathrm{~h}$.

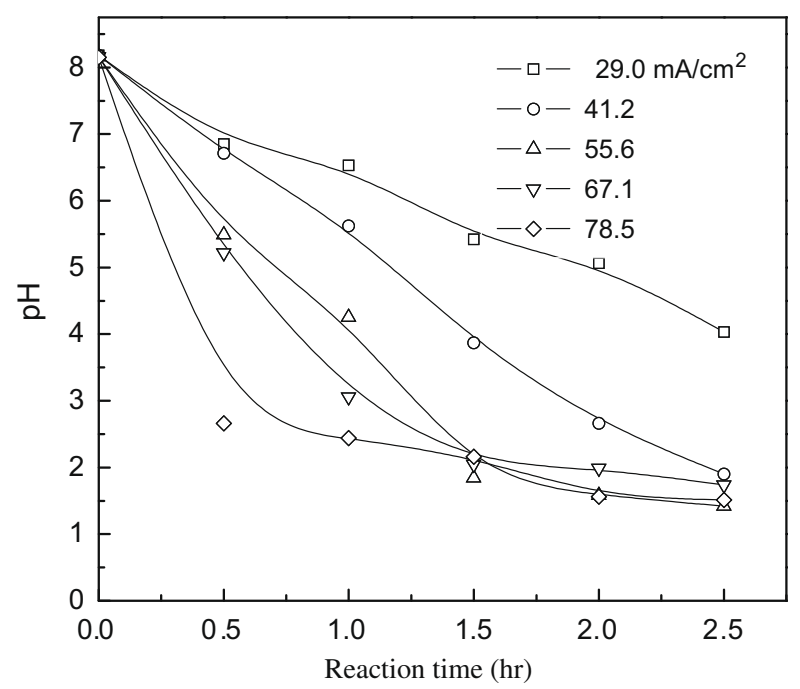

Fig. 5. Variation of solution $\mathrm{pH}$ in $\mathrm{PEC}$ reaction with various current densities.

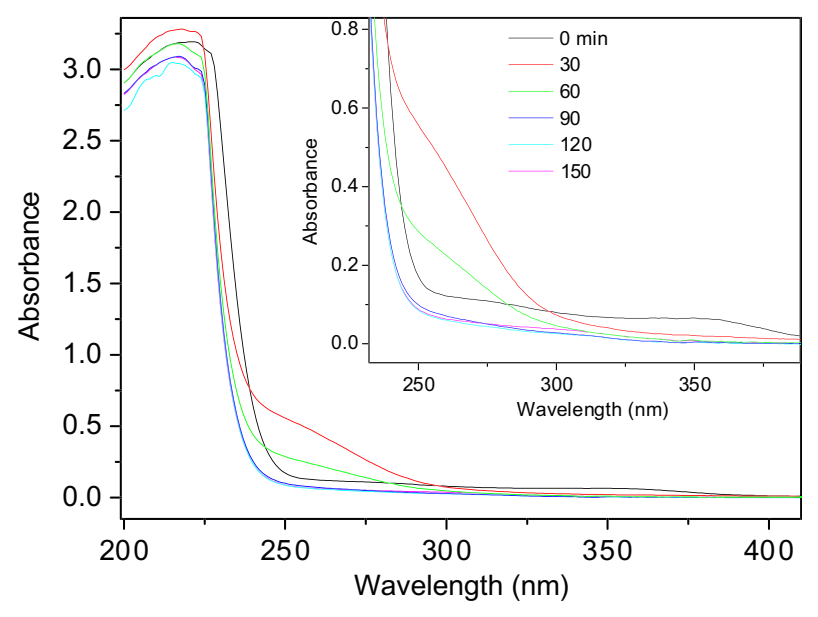

Fig. 6. Variation of solution UV-vis spectra of landfill leachate with the reaction time in the photoelectrocatalytic process (applied current density of $67.1 \mathrm{~mA} / \mathrm{cm}^{2}$ ).

Table 2

The concentration variation of metal ions in the landfill leachate.

\begin{tabular}{lccl}
\hline $\begin{array}{l}\text { Metal } \\
\text { ions }\end{array}$ & $\begin{array}{c}\text { Raw } \\
\text { water }\end{array}$ & $\begin{array}{l}\text { After PEC treatment without } \\
\text { pH adjustment }\end{array}$ & $\begin{array}{l}\text { After PEC treatment with } \\
\text { pH adjustment }\end{array}$ \\
\hline $\mathrm{Fe}$ & 8.96 & 9.46 & 1.95 \\
$\mathrm{Cu}$ & 4.18 & 6.83 & 0.94 \\
$\mathrm{Zn}$ & 17.75 & 21.24 & 2.04 \\
$\mathrm{~Pb}$ & 0.07 & 0.10 & $\mathrm{UD}$ \\
$\mathrm{Cd}$ & 0.012 & 0.01 & $\mathrm{UD}$ \\
$\mathrm{Cr}$ & 2.06 & 0.96 & 0.19 \\
$\mathrm{Mn}$ & 1.46 & 1.85 & 0.02 \\
\hline
\end{tabular}

Current density of $67.1 \mathrm{~mA} / \mathrm{cm}^{2}$; reaction time of $2.5 \mathrm{~h}$; UD, undetected.

At the meantime, the metal ions in the landfill leachate before and after PEC treatment were analyzed (Table 2). It is shown that the concentrations of nearly all metal ions increased after PEC treatment. It is measured that the $\mathrm{pH}$ value was decreased to 2.0 after PEC process. In this case, many metal oxides or complexes will dissolve into metal ions, which are responsible for the concentration increase of metal ions. Furthermore, the $\mathrm{pH}$ was adjusted from 2.0 to 6.0. It is seen that the concentration of all metals ions decreased largely.

In PEC degradation of landfill leachate, some chlorinated byproducts will be generated by the indirect oxidation effect of chlorine/hypochlorite. However, the undesired byproducts can be removed after PEC reaction for a relatively long time (Chiang et al., 2002). Meanwhile, their studies indicate that chlorination of humic acid conducted by electrochemical oxidation process produces less absorbable halogenated compounds than the chlorination conducted by $\mathrm{HOCl}$ oxidation. Therefore, $\mathrm{PEC}$ process can be concluded to be environmentally friendly for the treatment of landfill leachate than the individual electro-oxidation process.

\section{Conclusions}

The results have shown that PEC treatment is a more promising process for the degradation and remediation of effluents of low biodegradability in landfill leachate than single electrolysis method. At a current density of $67.1 \mathrm{~mA} / \mathrm{cm}^{2}$ and $2.5 \mathrm{~h}$ reaction time, the removal rates achieved were for $74.1 \%$ COD, $41.6 \%$ for TOC, and $94.5 \%$ for ammonium in the electrolysis process with UV light irradiation. In comparison, the removal rates of COD, TOC, and ammonium were decreased in the individual electrolysis process, 
respectively. PEC oxidation of landfill leachate under appropriate conditions can remove most COD and almost all ammonia, and also significantly remove color. Reduction of pollutants appears to be primarily due to indirect oxidation. The ammonia was removed and organic contaminants were degraded into small molecular acids. And, the total metal ions concentrations of $\mathrm{Fe}, \mathrm{Cu}, \mathrm{Zn}, \mathrm{Pb}$, $\mathrm{Cd}, \mathrm{Cr}$, and $\mathrm{Mn}$ decreased after $\mathrm{PEC}$ reaction with the $\mathrm{pH}$ adjustment.

\section{Acknowledgements}

This work was supported by the National Natural Science Foundation of China (Nos. 50538090, 20977103, 50778172, 20837001). This research was also supported by the Knowledge Innovation Program of the Chinese Academy of Sciences (RCEES-QN2007Z007) and the Special Funds for Young Scholars of RCEES, CAS.

\section{Appendix A. Supplementary material}

Supplementary data associated with this article can be found, in the online version, at doi:10.1016/j.biortech.2009.08.098.

\section{References}

Anglada, A., Urtiaga, A., Ortiz, I., 2009. Pilot scale performance of the electrooxidation of landfill leachate at boron-doped diamond anodes. Environ. Sci. Technol. 43, 2035-2040.

Cabeza, A., Urtiaga, A.M., Ortiz, I., 2007. Electrochemical treatment of landfill leachates using a boron-doped diamond anode. Ind. Eng. Chem. Res. 46, 14391446.

Chiang, L.-C., Chang, J.-E., Wen, T.-C., 1995a. Indirect oxidation effect in electrochemical oxidation treatment of landfill leachate. Water Res. 29, 671678.
Chiang, L.C., Chang, J.E., Wen, T.C., 1995b. Electrochemical treatability of refractory pollutants in landfill leachate. Hazard. Waste Hazard. Mater. 12, 71-82.

Chiang, L.-C., Chang, J.E., Wen, T.-C., 2002. Destruction of refractory humic acid by electrochemical oxidation process. Water Sci. Technol. 42 (3), 225-232.

Cho, S.P., Hong, S.C., Hong, S.-I., 2002. Photocatalytic degradation of the landfill leachate containing refractory matters and nitrogen compounds. Appl. Catal. B: Environ. 39, 125-133.

Cho, S.P., Hong, S.C., Hong, S.-I., 2004. Study of the end point of photocatalytic degradation of landfill leachate containing refractory matter. Chem. Eng. J. 98, 245-253.

Cossu, R., Polcaro, A.M., Lavagnolo, M.C., Mascia, M., Palmas, S., Renoldi, F., 1998. Electrochemical treatment of landfill leachate: oxidation at $\mathrm{Ti} / \mathrm{PbO}_{2}$ and $\mathrm{Ti} / \mathrm{SnO}_{2}$ anodes. Environ. Sci. Technol. 32, 3570-3573.

Deng, Y., Englehardt, J.D., 2006. Treatment of landfill leachate by the Fenton process. Water Res. 40, 3683-3694.

Fan, L., Zhang, H., Chang, C.-H., Lee, D.-J., He, P.-J., Shao, L.-M., Su, A., 2008. Dissolved organic matter and estrogenic potential of landfill leachate. Chemosphere 72, 1381-1386.

Lei, Y., Shen, Z., Huang, R., Wang, W., 2007. Treatment of landfill leachate by combined aged-refuse bioreactor and electro-oxidation. Water Res. 41, 24172426.

Moraes, P.B., Bertazzoli, R., 2005. Electrodegradation of landfill leachate in a flow electrochemical reactor. Chemosphere 58, 41-46.

Primo, O., Rueda, A., Rivero, M.J., Ortiz, I., 2008. An integrated process, Fenton reaction-ultrafiltration, for the treatment of landfill leachate: pilot plant operation and analysis. Ind. Eng. Chem. Res. 47, 946-952.

Renou, S., Givaudan, J.G., Poulain, S., Dirassouyan, F., Moulin, P., 2008. Landfill leachate treatment: review and opportunity. J. Hazard. Mater. 150, 468-493.

Rivas, F.J., Beltran, F. Carvalho, F. Gimeno, O., Frades, J, 2005. Study of different integrated physical-chemical + adsorption processes for landfill leachate remediation. Ind. Eng. Chem. Res. 44, 2871-2878.

Salem, Z., Hamouri, K., Djemaa, R., Allia, K., 2008. Evaluation of landfill leachate pollution and treatment. Desalination 220, 108-114.

Tauchert, E., Schneider, S., de Morais, J.L., Peralta-Zamora, P., 2006. Photochemically-assisted electrochemical degradation of landfill leachate. Chemosphere 64, 1458-1463.

Wu, J.J., Wu, C.-C., Ma, H.-W., Chang, C.-C., 2004. Treatment of landfill leachate by ozone-based advanced oxidation processes. Chemosphere 54, 997-1003. 